\title{
Reproductive hormonal variations and adenohypophyseal lesions in pre-pubertal buffalo heifers inoculated with Pasteurella multocida type B: 2 and its immunogens
}

Faez Firdaus Abdullah Jesse ${ }^{1,2^{*}}$, Hayder Hamzah Ibrahim ${ }^{1,3}$, Yusuf Abba ${ }^{4 *}$, Eric Lim Teik Chung ${ }^{1}$, Ali Dhiaa Marza ${ }^{1,5}$, Mazlina Mazlann, Mohd Zamri-Saad ${ }^{4}$, Abdul Rahman Omar ${ }^{6}$, Md Zuki Abu Bakar Zakaria ${ }^{6}$, Abdul Aziz Saharee ${ }^{1}$, Abd Wahid Haron ${ }^{1}$ and Mohd Azmi Mohd Lila ${ }^{4}$

\begin{abstract}
Background: Hemorrhagic septicemia is a fatal disease of cattle and buffaloes caused by P. multocida. Although the pathogenesis of the bacteria has been well established in literature, there is a paucity of information on the possible role of the bacteria and its immunogens; lipopolysaccharide (LPS) and outer membrane proteins (OMPs) on the reproductive capacity of buffalo heifers.
\end{abstract}

Methods: In this study, twenty one healthy prepubertal female buffaloes aged 8 months were divided into seven groups of 3 buffaloes each (G1-G7). Group 1 (G1) served as the negative control group and were inoculated orally with $10 \mathrm{~mL}$ sterile Phosphate Buffer Saline (PBS), groups 2 (G2) and 3 (G3) were inoculated orally and subcutaneously with $10 \mathrm{~mL}$ of $10^{12}$ colony forming unit (cfu) of P.multocida type B: 2, while groups 4 (G4) and 5 (G5) received $10 \mathrm{~mL}$ of bacterial LPS orally and intravenously, respectively. Lastly, groups 6 (G6) and 7 (G7) were orally and subcutaneously inoculated with $10 \mathrm{~mL}$ of bacterial OMPs. Whole blood was collected in EDTA vials at stipulated time points (0, 2, 4, 6, $8,10,12,24,36,48,72,120,168,216,264,312,360,408,456$ and 504 h), while tissue sections of the pituitary glands were collected and transported to the histopathology laboratory in 10\% buffered formalin for processing and Hematoxylin and eosin staining. Plasma levels of luteinizing hormone (LH), follicle stimulating hormone (FSH) , progesterone (PG), estradiol (EST) and gonadotrophin releasing hormone $(\mathrm{GnRH})$ were determined.

Results: The histopathological lesions observed in the pituitary gland included hemorrhage, congestion, inflammatory cell infiltration, hydropic degeneration, necrosis and edema. These changes were higher $(p<0.05)$ in distribution and severity in G3, G6 and G7. Hormonal concentrations of LH, FSH, PG, EST and GnRH declined in all inoculation groups as time elapsed and were lower $(p<0.05)$ than that of the control group.

Conclusion: Based on these findings, P.multocida B: 2 and its immunogens can be said to negatively affect the hypothalamic-pituitary-gonadal axis, resulting in decreased levels of reproductive hormones which may predispose to infertility in buffalo heifers.

Keywords: Hemorrhagic septicemia, Reproductive hormones, Pituitary gland, Outer membrane protein, Lipopolysaccharide, Buffaloes

\footnotetext{
*Correspondence: jesseariasamy@gmail.com; yabbavet@gmail.com

${ }^{1}$ Department of Veterinary Clinical Studies, Faculty of Veterinary Medicine,

Universiti Putra Malaysia, 43400 Serdang, Malaysia

${ }^{4}$ Department of Veterinary Pathology and Microbiology, Faculty of Veterinary

Medicine, Universiti Putra Malaysia, 43400 Serdang, Malaysia

Full list of author information is available at the end of the article
}

(c) The Author(s). 2017 Open Access This article is distributed under the terms of the Creative Commons Attribution 4.0 International License (http://creativecommons.org/licenses/by/4.0/, which permits unrestricted use, distribution, and reproduction in any medium, provided you give appropriate credit to the original author(s) and the source, provide a link to the Creative Commons license, and indicate if changes were made. The Creative Commons Public Domain Dedication waiver (http://creativecommons.org/publicdomain/zero/1.0/) applies to the data made available in this article, unless otherwise stated. 


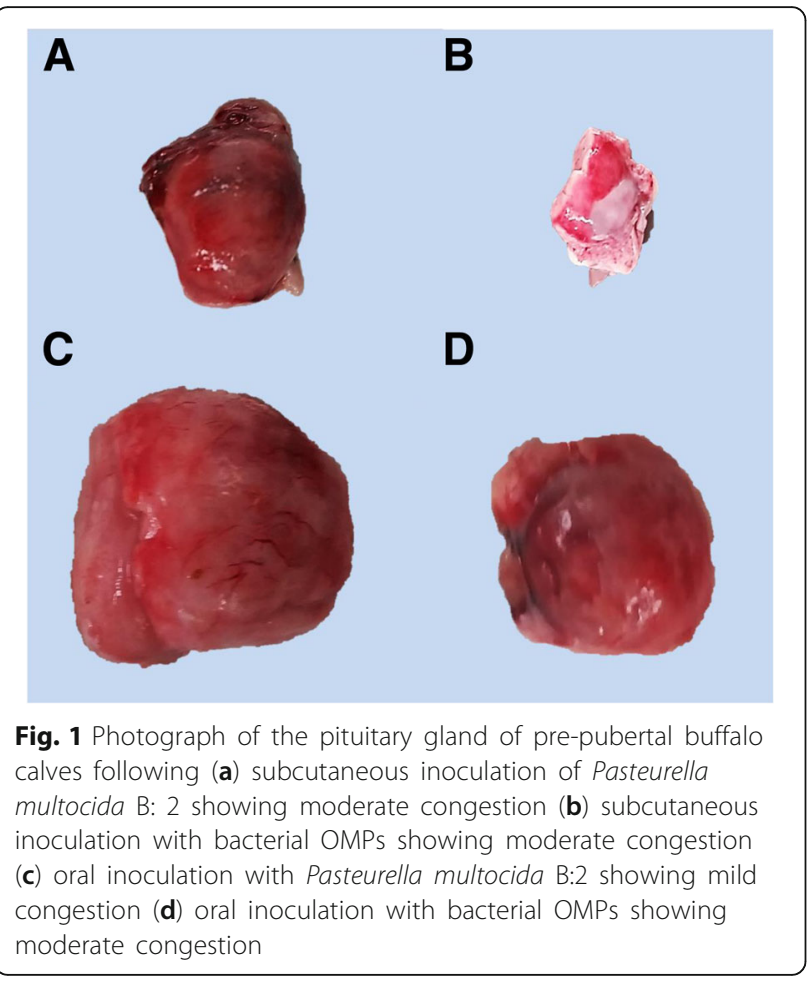

\section{Background}

Haemorrhagic Septicaemia (HS) is an important disease of cattle and buffaloes caused by Pasteurella multocida [1]. It can be described as an acute, fatal septicemic disease caused by specific serotypes of Pasteurella multocida. P. multocida contains lipopolysaccharide (LPS), which is an important component of the outer cell wall of the organism [2-4]. The LPS are released during bacterial multiplication or death, resulting in an inflammatory reaction in the host animal. The LPS is part of the bacterial endotoxin and plays an important role in the pathogenesis of the disease [5, 6]. Another immunogen of $P$. multocida is a $37 \mathrm{kd}$ outer membrane proteins
(OMPs), which is one of the most important virulence factors of Pasteurella multocida type B: 2 . The components of the bacterial outer membrane such as trans membrane proteins and lipoproteins play key roles in the interaction of the pathogen with the host environment and in the host immune response to infection [7]. Both the LPS and OMPs showed to induce immunogenic responses in laboratory animals and hence useful in the development of immunogenic vaccines $[5,8]$.

In our previous studies, both $P$. multocida and its immunogen; LPS induced pathological lesions in the reproductive system and pituitary glands of both male and female mice. Furthermore, we also reported changes in the hormonal profiles of estrogen, progesterone and testosterone in the infected mice [9]. Recently, we also reported histopathological changes in the reproductive tract of buffalo heifers infected with P. multocida and its immunogen; LPS and OMPs $[10,11]$. The studies above all showed the possibility of $P$. multocida and its immunogens to induce reproductive dysfunction, which may result in infertility in infected animals. However, since the pituitary gland and associated hormones play vital roles in the reproductive cycle of female animals, we hypothesized that P. multocida and its immunogen; LPS and OMPs will cause changes in reproductive hormonal levels and pathology in the pituitary gland of pre-pubertal female buffaloes.

\section{Methods}

Animal housing, grouping and inoculation

The animals were housed in pens with concrete floors. At the commencement of the experiment, the animals were divided into their respective inoculation groups and housed separately. Food and water were provided ad libatum. Twenty one healthy prepubertal female buffaloes aged 8 months were used for this study. Preparation of P. multocida type B: 2 culture was done as described

Table 1 Mean score of cellular changes in the pituitary gland of Pre-pubertal Buffalo heifers inoculated with Pasteurella multocida B: 2 and its immunogens (LPS and OMPS)

\begin{tabular}{|c|c|c|c|c|c|}
\hline \\
\hline \multicolumn{6}{|l|}{$\begin{array}{l}\text { Parameters } \\
\text { Groups }\end{array}$} \\
\hline $\begin{array}{l}\text { Groups } \\
\text { Group } 1 \text { (PBS Control) }\end{array}$ & \multicolumn{5}{|c|}{ Group 1 (PBS Control) } \\
\hline \multicolumn{6}{|l|}{ Group 2 (P.multocida B:2 Oral) } \\
\hline \multicolumn{6}{|l|}{ Group 3 (P.multocida B:2 Subcutaneous) } \\
\hline \multicolumn{6}{|l|}{ Group 4 (LPS Oral) } \\
\hline \multicolumn{6}{|l|}{ Group 5 (LPS Intravenous) } \\
\hline Group 6 (OMP Oral) & $2.58 \pm 0.18^{b}$ & $0.33 \pm 0.14^{\mathrm{a}}$ & $1.35 \pm 0.15^{c}$ & $2.31 \pm 0.15^{c}$ & $0.50 \pm 0.17^{b}$ \\
\hline Group 7 (OMP Subcutaneous) & $2.75 \pm 0.18^{c}$ & $0.42 \pm 0.14^{b}$ & $1.55 \pm 0.10^{c}$ & $2.44 \pm 0.12^{c}$ & $0.42 \pm 0.11^{b}$ \\
\hline
\end{tabular}

All values are expressed as mean $\pm \mathrm{SE} ; \mathrm{a}, \mathrm{b}, \mathrm{c}$ values with superscript within columns are significantly different at $P<0.05$ 
previously [10], while the LPS and OMPs were extracted as previously described [11].

Briefly, LPS was extracted using Intron Biotechnology LPS extraction kit. $5 \mathrm{~mL}$ of the bacterial cell suspension containing $10^{12} \mathrm{cfu}$ of $P$. multocida was centrifuged at 13, $000 \mathrm{rpm}$ for $30 \mathrm{~s}$ at room temperature. Extraction was done as stated in the manufacturer's protocol (http://eng.intronbio.com/PROTO-PDF/LPS\%20Extraction\%20Kit.pdf). SDS-PAGE was used to confirm the absence of protein in the extracted LPS.

The extraction of OMPs was carried out by freezing freshly harvested bacterial cell pellets for $24 \mathrm{~h}$ prior to extraction. The cell pellets were thawed for $15 \mathrm{~min}$ on ice and re-suspended in $10 \mathrm{~mL}$ of native lysis buffer. The cells were then incubated on ice for $30 \mathrm{~min}$ followed by centrifugation at $14,000 \mathrm{rpm}$ for $30 \mathrm{~min}$ at $4{ }^{\circ} \mathrm{C}$. The resultant supernatant containing the soluble fraction of the bacterial outer membrane proteins was retained and used in this study [11]. The female buffaloes were divided into seven groups of 3 buffaloes each (G1-G7). Group 1 (G1) served as the negative control group and were inoculated orally with $10 \mathrm{~mL}$ sterile Phosphate Buffer Saline (PBS), groups 2 (G2) and 3 (G3) were inoculated orally and subcutaneously with $10 \mathrm{~mL}$ of $10^{12}$ colony forming unit (cfu) of P.multocida type B: 2, while groups 4 (G4) and 5 (G5) received $10 \mathrm{~mL}$ of bacterial LPS orally and intravenously, respectively. Lastly, groups 6 (G6) and 7 (G7) were orally and subcutaneously inoculated with $10 \mathrm{~mL}$ of bacterial
OMPs. The animals were monitored every hour for clinical signs or signs of distress.

\section{Exsanguination of animals}

After $12 \mathrm{~h}$ of inoculation, calves from P.multocida subacute inoculation group were showing severe signs of respiratory distress and recumbency and had to be euthanized in order to minimize pain and suffering. Similarly, after $72 \mathrm{~h}$, calves from the OMPs subacute inoculation group were also exhibiting severe signs of respiratory distress and recumbency and were also euthanized. All calves from the other groups survived to the end of the experimental period (21 days) and were euthanized at 21 days. Euthanasia was carried out by exsanguination after the animals were anesthetized with Xylazine $(1 \mathrm{mg} / \mathrm{kg})$.

\section{Sample collection and processing}

Whole blood was collected in EDTA vials at stipulated time points $(0,2,4,6,8,10,12,24,36,48,72,120,168,216,264$, 312, 360, and 408, 456 and 504 h). The blood was centrifuged at 2, 400×g for $10 \mathrm{~min}$ to collect the plasma. Following the euthanasia of animals in G3 and G7, at $24 \mathrm{~h}$ and $72 \mathrm{~h}$, and other animals at 21 days, the pituitary glands were grossly examined for changes and tissue samples of the pituitary glands were collected and transported to the histopathology laboratory in $40 \%$ buffered formalin. Fixed tissue samples were processed by serial dehydration in ethanol, embedding in paraffin, sectioning at $4 \mu \mathrm{m}$ and staining with Hematoxylin and Eosin (H\&E). Stained slides were

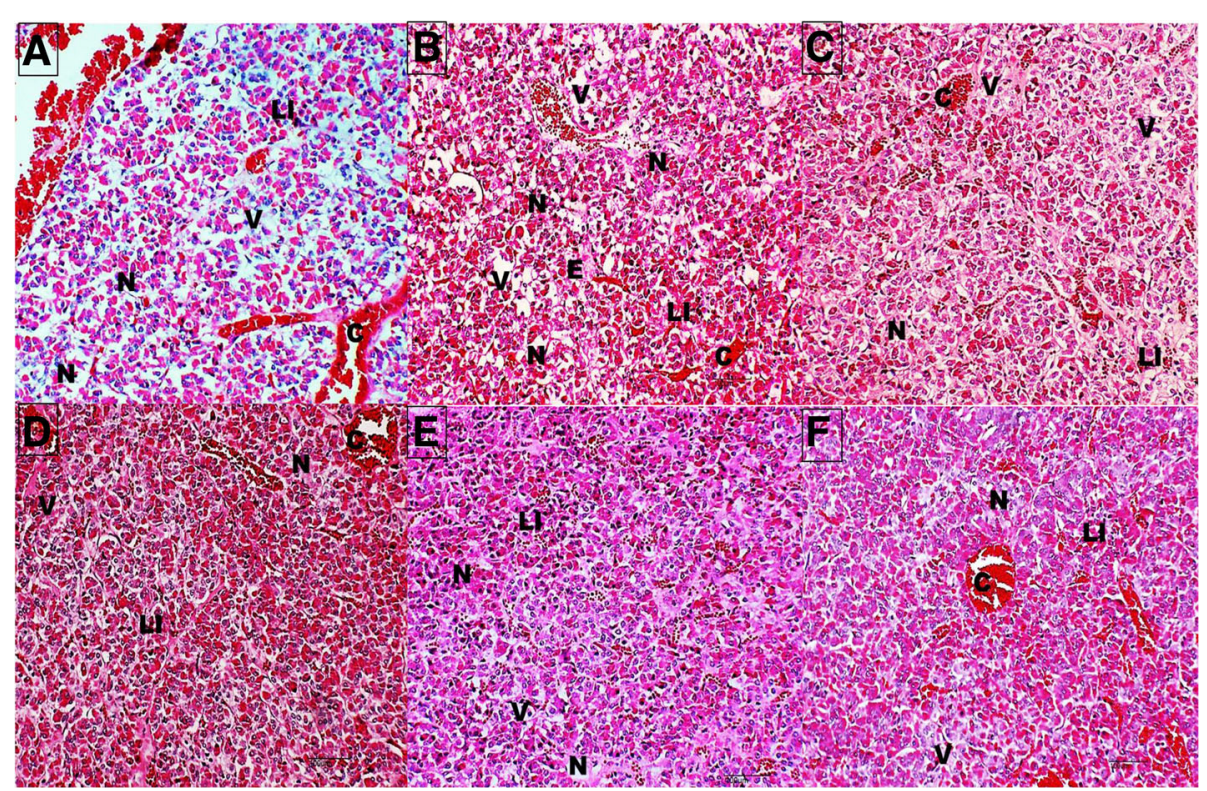

Fig. 2 Photomicrograph section of the anterior pituitary gland from different inoculation groups (a) P. multocida type B:2 subcutaneous inoculation (b) OMPs subcutaneous inoculation (c) OMPs oral inoculation (d) LPS intravenous inoculation (e) LPS oral inoculation (f) P. multocida B:2 oral inoculation groups showing vascular congestion (c) and presence of leucocytic infiltration (LI) around cells (Basophils) undergoing hydropic/vacuolar degeneration $(V)$ and necrosis $(N)$, note also the presence of edema $(\mathbf{e}), \mathrm{H} \& \mathrm{E} \times 200$ 
examined under light microscopy at $200 \mathrm{X}$ for lesions suggestive of infection such as hemorrhage, congestion, inflammatory cell infiltration, degeneration, necrosis and edema. From each tissue section, a total of 6-10 microscopic focal areas were evaluated and scored for lesion severity. Lesions were scored by using a grading scale of 0 (none), 1 (mild), 2 (moderate) and 3 (severe) based on the distribution in the microscope focus as previously described [12].

\section{Evaluation of reproductive hormonal levels}

Radio immunoassay (RIA) Kits (Immunotech, Beckman Coulter, U.S.A) were used for the plasma detection of luteinizing hormone (LH), follicle stimulating hormone (FSH), progesterone (PG) and estradiol (EST), while gonadotrophin releasing hormone $(\mathrm{GnRH})$ was determined with an ELISA kit (Qayee Bio, China). All protocols followed were based on the manufacturer's instructions without any modifications. Briefly, in the RIA hormonal evaluation for $\mathrm{LH}$ and FSH, the plasma sample was added to $100 \mu \mathrm{L}$ of calibrator which was mixed with
$50 \mu \mathrm{L}$ of tracer and added to antibody coated tubes. The tubes were covered and incubated for $90 \mathrm{~min}$ at $37{ }^{\circ} \mathrm{C}$. Count bound per minute was determined using Wallac Wizard Gamma Counter model 1470. The determination of EST and PG were done using the methods previously described by Jesse et al. [13], while GnRH concentration was determined by preparing sample and standard as outlined in the manufacturer's instructions. Briefly, both sample and standard were added with HRPconjugate reagent and incubated for $60 \mathrm{~min}$ at $37{ }^{\circ} \mathrm{C}$. The 96 well plate was washed five times and chromogen solution A,B was added. The plate was incubated for $10 \mathrm{~min}$ at $37^{\circ} \mathrm{C}$ and the optical density was measured at $450 \mathrm{~nm}$.

\section{Statistical analysis}

Hormonal concentrations were summarized into mean and standard error of means and analysed using Graph Pad Prism (Version 6.0), with Kruskal Wallis test (nonparametric) with Dunn's multiple comparison. Statistical significance was set at $p<0.05$.

Table 2 Changes in mean concentration of Gonadotropin-releasing hormone ( $G n R H)$ in prepubertal buffalo heifers following inoculation with Pasteurella multocida B: 2 and its immunogens (LPS and OMP)

\begin{tabular}{|c|c|c|c|c|c|c|c|}
\hline \multirow[t]{2}{*}{$\begin{array}{l}\text { Time } \\
\text { (hr) }\end{array}$} & \multirow{2}{*}{$\begin{array}{l}\text { Inoculated with } \\
\text { phosphate buffer saline } \\
\text { Control -G1 }\end{array}$} & \multirow{2}{*}{$\begin{array}{l}\text { Inoculated with } \\
\text { P.multocida B:2 } \\
\text { Oral route -G2 }\end{array}$} & \multirow[b]{2}{*}{$\begin{array}{l}\text { Subcute } \\
\text { route - G3 }\end{array}$} & \multicolumn{2}{|c|}{$\begin{array}{l}\text { Inoculated with LPS extracted } \\
\text { from } \\
\text { P.multocida B:2 }\end{array}$} & \multicolumn{2}{|c|}{$\begin{array}{l}\text { Inoculated with OMPs extracted } \\
\text { from } \\
\text { P.multocida } \mathrm{B}: 2\end{array}$} \\
\hline & & & & $\begin{array}{l}\text { Oral } \\
\text { route- G4 }\end{array}$ & $\begin{array}{l}\text { Intravenous } \\
\text { route - G5 }\end{array}$ & $\begin{array}{l}\text { Oral } \\
\text { route- G } 6\end{array}$ & $\begin{array}{l}\text { Subcute } \\
\text { route - G7 }\end{array}$ \\
\hline$\overline{0}$ & $218.5 \pm 3.4^{a b}$ & $214.2 \pm 0.1^{a b}$ & $218.2 \pm 0.01^{a}$ & $221.6 \pm 2.1^{a}$ & $212.8 \pm 0.2^{\mathrm{ab}}$ & $215.7 \pm 0.1^{a b}$ & $205.7 \pm 0.3^{c}$ \\
\hline 2 & $222.6 \pm 3.6^{a}$ & $169.1 \pm 0.0^{b}$ & $155.4 \pm 1.1^{b}$ & $207.5 \pm 0.2^{c}$ & $201.6 \pm 0.0^{c}$ & $186.1 \pm 1.9^{d}$ & $154.9 \pm 0.2^{b}$ \\
\hline 4 & $222.2 \pm 6.1^{a}$ & $152.7 \pm 0.02^{b}$ & $155.4 \pm 0.0^{b}$ & $186.2 \pm 0.01^{c}$ & $181.6 \pm 0.01^{c}$ & $173.8 \pm 0.1^{d}$ & $157.2 \pm 0.0^{b}$ \\
\hline 6 & $217.4 \pm 3.4^{a}$ & $148.6 \pm 1.1^{b}$ & $140.1 \pm 1.0^{c}$ & $170.7 \pm 1.0^{d}$ & $167.5 \pm 0.2^{d}$ & $169.2 \pm 2.1^{d}$ & $139.5 \pm 2.3^{c}$ \\
\hline 8 & $210.9 \pm 10.7^{a}$ & $144.9 \pm 0.0^{b}$ & $111.9 \pm 0.1^{c}$ & $164.1 \pm 0.0^{d}$ & $167.9 \pm 2.1^{d}$ & $165.5 \pm 0.02^{d}$ & $120.9 \pm 2.1^{\mathrm{e}}$ \\
\hline 10 & $209.9 \pm 7.1^{a}$ & $143.1 \pm 0.1^{b}$ & $86.5 \pm 0.1^{c}$ & $158.4 \pm 0.2^{d}$ & $147.7 \pm 0.1^{b}$ & $158.7 \pm 0.0^{d}$ & $119.6 \pm 2.3^{e}$ \\
\hline 12 & $212.2 \pm 2.9^{a}$ & $130.8 \pm 0.1^{b}$ & $82.9 \pm 0.0^{c}$ & $151.5 \pm 1.1^{d}$ & $145.1 \pm 0.0^{e}$ & $158.3 \pm 0.01^{f}$ & $101.0 \pm 0.8^{g}$ \\
\hline 24 & $217.4 \pm 6.6^{a}$ & $138.7 \pm 1.0^{b}$ & & $148.0 \pm 0.1^{c}$ & $140.7 \pm 0.2^{b}$ & $147.4 \pm 0.01^{c}$ & $121.7 \pm 0.0^{d}$ \\
\hline 36 & $217.9 \pm 2.5^{a}$ & $127.3 \pm 0.0^{b}$ & & $137.7 \pm 0.1^{c}$ & $130.4 \pm 0.3^{d}$ & $134.6 \pm 1.02^{c}$ & $107.6 \pm 0.02^{e}$ \\
\hline 48 & $215.1 \pm 0.0^{a}$ & $114.3 \pm 5.7^{b}$ & & $129.7 \pm 0.2^{c}$ & $122.8 \pm 1.1^{d}$ & $126.8 \pm 0.1^{c}$ & $105.9 \pm 0.0^{e}$ \\
\hline 60 & $218.5 \pm 1.9^{a}$ & $111.8 \pm 0.1^{b}$ & & $113.8 \pm 0.02^{b}$ & $119.3 \pm 0.01^{c}$ & $108.3 \pm 0.2^{b}$ & $78.3 \pm 1.9^{d}$ \\
\hline 72 & $220.0 \pm 3.2^{a}$ & $96.3 \pm 1.1^{b}$ & & $110.2 \pm 0.1^{c}$ & $113.9 \pm 0.2^{c}$ & $110.1 \pm 0.0^{c}$ & $88.1 \pm 0.0^{d}$ \\
\hline 120 & $214.9 \pm 2.2^{a}$ & $94.3 \pm 0.9^{b}$ & & $109.9 \pm 0.7^{b d}$ & $106.9 \pm 0.3^{b}$ & $120.2 \pm 1.1^{\mathrm{bd}}$ & \\
\hline 168 & $216.5 \pm 8.5^{a}$ & $84.7 \pm 4.9^{b}$ & & $104.5 \pm 0.6^{\mathrm{cd}}$ & $102.9 \pm 1.2^{c}$ & $112.6 \pm 1.5^{d}$ & \\
\hline 216 & $215.3 \pm 5.8^{a}$ & $91.2 \pm 0.0^{b}$ & & $101.6 \pm 1.2^{c}$ & $98.4 \pm 0.01^{c}$ & $106.5 \pm 1.2^{d}$ & \\
\hline 264 & $218.9 \pm 5.3^{a}$ & $89.3 \pm 0.2^{b}$ & & $100.4 \pm 2.2^{c}$ & $95.3 \pm 2.1^{b}$ & $100.6 \pm 2.1^{c}$ & \\
\hline 312 & $218.6 \pm 3.6^{a}$ & $85.7 \pm 2.3^{b}$ & & $93.2 \pm 0.01^{c}$ & $88.9 \pm 1.1^{b}$ & $95.9 \pm 0.2^{c}$ & \\
\hline 360 & $218.6 \pm 7.1^{a}$ & $78.8 \pm 1.0^{\mathrm{b}}$ & & $85.3 \pm 2.1^{c}$ & $83.2 \pm 2.1^{c}$ & $99.9 \pm 2.3^{d}$ & \\
\hline 408 & $215.1 \pm 0.1^{a}$ & $77.3 \pm 1.9^{b}$ & & $74.4 \pm 0.02^{b}$ & $76.1 \pm 0.2^{c}$ & $87.6 \pm 4.7^{c}$ & \\
\hline 456 & $216.5 \pm 2.9^{a}$ & $75.3 \pm 0.3^{b}$ & & $62.1 \pm 0.0^{c}$ & $74.3 \pm 0.3^{b}$ & $76.7 \pm 0.5^{b}$ & \\
\hline 504 & $218.1 \pm 4.8^{a}$ & $74.1 \pm 0.1^{b}$ & & $62.5 \pm 0.02^{c}$ & $72.2 \pm 0.9^{b}$ & $75.4 \pm 0.7^{b}$ & \\
\hline
\end{tabular}




\section{Results}

\section{Clinical findings}

The clinical findings observed in the inoculation groups have been described in an earlier study by Ibrahim et al. $[10,11]$. Briefly, fever was observed in all the groups for at least 3 days post inoculation. Respiratory distress and mucopurulent discharge were mild in groups G2, G4, G5 and G6, while groups G3 and G7 developed severe signs and had to be euthanized. The mucous membrane was normal in G2, G4 and G6, while slight congestion was observed in G5 and moderate to severe in G3 and G7.

\section{Gross and histopathological lesions in the pituitary glands}

The most obvious gross change observed in pituitary gland was congestion, which was mild to moderate in G3, G6 and G7, and mild G2, G4 and G5. The negative control animals did not show any lesions at postmortem examination (Fig. 1).

The histopathological lesions observed in the pituitary gland are summarized in Table 1. Hemorrhage and congestion were higher $(p<0.05)$ in G3 and G7.Inflammatory cell responses typified by infiltrations of neutrophils and lymphocyte was comparable in all groups $(p>0.05)$, but higher $(p<0.05)$ in G7. Hydropic degeneration characterized by presence of vacuoles were commonly observed in the basophils than in the acidophils. Necrosis was characterized by nuclear pyknosis and karyorrhexis and in some instances complete nuclear karyolysis. Both degeneration and necrosis were comparable and lower $(p>0.05)$ in G2, G4 and G5, and higher $(p<0.05)$ in G3, G6 and G7. Edema was comparable and higher in G3, G6 and G7 (Fig. 2).

\section{Reproductive hormone analysis Gonadotrophin releasing hormone concentration}

The changes in the mean concentration of $\mathrm{GnRH}$ in all groups are summarized in Table 2. The concentration of GnRH was lower $(p<0.05)$ in all the inoculation groups from $2 \mathrm{~h}$ of infection and kept declining as the time of inoculation progressed. After $12 \mathrm{~h}, \mathrm{GnRH}$ was low $(p<0.05)$ in the G3. By 24, 36, 48, 60 and $72 \mathrm{~h}$ of inoculation, GnRH was lower $(p<0.05)$ in G7 when compared to other groups. After $504 \mathrm{~h}, \mathrm{GnRH}$ concentration was lower

Table 3 Changes in mean concentration of Follicle stimulating hormone in prepubertal buffalo heifers following inoculation with Pasteurella multocida B: 2 and its immunogens (LPS and OMP)

\begin{tabular}{|c|c|c|c|c|c|c|c|}
\hline \multirow[t]{2}{*}{$\begin{array}{l}\text { Time } \\
\text { (hr) }\end{array}$} & \multirow{2}{*}{$\begin{array}{l}\text { Inoculated with PBS } \\
\text { Control -G1 }\end{array}$} & \multirow{2}{*}{$\begin{array}{l}\text { Inoculated with } \\
\text { P.multocida } \mathrm{B}: 2 \\
\text { Oral route -G2 }\end{array}$} & \multirow[b]{2}{*}{$\begin{array}{l}\text { Subcutaneous } \\
\text { route - G3 }\end{array}$} & \multicolumn{2}{|c|}{$\begin{array}{l}\text { Inoculated with LPS extracted } \\
\text { from P.multocida B:2 }\end{array}$} & \multicolumn{2}{|c|}{$\begin{array}{l}\text { Inoculated with OMPs extracted } \\
\text { from P.multocida B:2 }\end{array}$} \\
\hline & & & & $\begin{array}{l}\text { Oral } \\
\text { route- G4 }\end{array}$ & $\begin{array}{l}\text { Intravenous } \\
\text { route - G5 }\end{array}$ & $\begin{array}{l}\text { Oral } \\
\text { route- G } 6\end{array}$ & $\begin{array}{l}\text { Subcutaneous } \\
\text { route - G7 }\end{array}$ \\
\hline 0 & $0.32 \pm 0.01^{a}$ & $0.31 \pm 0.00^{a}$ & $0.33 \pm 0.01^{a}$ & $0.32 \pm 0.01^{a}$ & $0.33 \pm 0.01^{a}$ & $0.32 \pm 0.00^{a}$ & $0.32 \pm 0.00^{a}$ \\
\hline 2 & $0.32 \pm 0.01^{\mathrm{ab}}$ & $0.30 \pm 0.00^{b c}$ & $0.27 \pm 0.01^{c}$ & $0.32 \pm 0.00^{\mathrm{ab}}$ & $0.33 \pm 0.00^{a}$ & $0.30 \pm 0.00^{a b c}$ & $0.31 \pm 0.01^{\mathrm{abc}}$ \\
\hline 4 & $0.31 \pm 0.00^{a b}$ & $0.29 \pm 0.00^{b c d}$ & $0.25 \pm 0.02^{d}$ & $0.31 \pm 0.00^{a}$ & $0.31 \pm 0.01^{a b c}$ & $0.29 \pm 0.00^{a b c}$ & $0.28 \pm 0.01^{c d}$ \\
\hline 6 & $0.30 \pm 0.00^{a}$ & $0.28 \pm 0.01^{a}$ & $0.24 \pm 0.01^{a}$ & $0.30 \pm 0.00^{a}$ & $0.29 \pm 0.02^{a}$ & $0.29 \pm 0.01^{a}$ & $0.27 \pm 0.01^{a}$ \\
\hline 8 & $0.33 \pm 0.00^{a}$ & $0.28 \pm 0.01^{b}$ & $0.23 \pm 0.00^{b}$ & $0.29 \pm 0.00^{\mathrm{ab}}$ & $0.28 \pm 0.01^{\mathrm{ab}}$ & $0.28 \pm 0.01^{a b}$ & $0.25 \pm 0.02^{b}$ \\
\hline 10 & $0.32 \pm 0.00^{a}$ & $0.26 \pm 0.01^{b}$ & $0.21 \pm 0.01^{b}$ & $0.29 \pm 0.01^{\mathrm{ab}}$ & $0.27 \pm 0.01^{b}$ & $0.27 \pm 0.01^{b}$ & $0.24 \pm 0.02^{b}$ \\
\hline 12 & $0.33 \pm 0.00^{a}$ & $0.26 \pm 0.00^{b c}$ & $0.19 \pm 0.00^{d}$ & $0.28 \pm 0.01^{b}$ & $0.25 \pm 0.01^{b c}$ & $0.26 \pm 0.01^{b c}$ & $0.23 \pm 0.00^{c}$ \\
\hline 24 & $0.31 \pm 0.00^{a}$ & $0.25 \pm 0.02^{b}$ & & $0.27 \pm 0.01^{b}$ & $0.25 \pm 0.01^{b}$ & $0.25 \pm 0.01^{b}$ & $0.21 \pm 0.01^{b}$ \\
\hline 36 & $0.32 \pm 0.01^{a}$ & $0.24 \pm 0.01^{b}$ & & $0.27 \pm 0.02^{b}$ & $0.24 \pm 0.00^{b}$ & $0.23 \pm 0.02^{b}$ & $0.20 \pm 0.0^{b}$ \\
\hline 48 & $0.31 \pm 0.01^{a}$ & $0.24 \pm 0.01^{b c}$ & & $0.26 \pm 0.00^{b}$ & $0.23 \pm 0.01^{b c}$ & $0.23 \pm 0.01^{b c}$ & $0.20 \pm 0.00^{c}$ \\
\hline 60 & $0.31 \pm 0.00^{a}$ & $0.23 \pm 0.00^{b}$ & & $0.24 \pm 0.00^{b}$ & $0.22 \pm 0.02^{b}$ & $0.21 \pm 0.02^{b}$ & $0.19 \pm 0.01^{b}$ \\
\hline 72 & $0.33 \pm 0.00^{a}$ & $0.23 \pm 0.01^{b}$ & & $0.22 \pm 0.01^{b}$ & $0.22 \pm 0.00^{b}$ & $0.21 \pm 0.01^{b}$ & $0.18 \pm 0.01^{b}$ \\
\hline 120 & $0.32 \pm 0.00^{a}$ & $0.21 \pm 0.00^{b}$ & & $0.22 \pm 0.02^{b}$ & $0.21 \pm 0.01^{a}$ & $0.2 \pm 0.00^{a}$ & \\
\hline 168 & $0.32 \pm 0.00^{a}$ & $0.19 \pm 0.00^{b}$ & & $0.22 \pm 0.00^{b}$ & $0.20 \pm 0.00^{b}$ & $0.20 \pm 0.01^{b}$ & \\
\hline 216 & $0.31 \pm 0.00 a$ & $0.18 \pm 0.01^{b}$ & & $0.19 \pm 0.01 b$ & $0.20 \pm 0.01^{b}$ & $0.19 \pm 0.02^{b}$ & \\
\hline 264 & $0.33 \pm 0.00^{a}$ & $0.18 \pm 0.01^{b}$ & & $0.21 \pm 0.01^{b}$ & $0.18 \pm 0.02^{b}$ & $0.18 \pm 0.02^{b}$ & \\
\hline 312 & $0.32 \pm 0.00^{a}$ & $0.17 \pm 0.01^{b}$ & & $0.21 \pm 0.01 b$ & $0.18 \pm 0.01 b$ & $0.19 \pm 0.01^{b}$ & \\
\hline 360 & $0.31 \pm 0.00^{a}$ & $0.17 \pm 0.01^{b}$ & & $0.19 \pm 0.003^{b}$ & $0.18 \pm 0.02^{b}$ & $0.18 \pm 0.01^{b}$ & \\
\hline 408 & $0.30 \pm 0.00^{a}$ & $0.16 \pm 0.00^{b}$ & & $0.19 \pm 0.01^{b}$ & $0.18 \pm 0.02^{b}$ & $0.18 \pm 0.00^{b}$ & \\
\hline 456 & $0.31 \pm 0.03^{a}$ & $0.16 \pm 0.01^{b}$ & & $0.18 \pm 0.01^{b}$ & $0.18 \pm 0.00 b$ & $0.18 \pm 0.01^{b}$ & \\
\hline 504 & $0.32 \pm 0.01^{a}$ & $0.16 \pm 0.01^{b}$ & & $0.17 \pm 0.01^{b}$ & $0.17 \pm 0.01^{b}$ & $0.16 \pm 0.00^{b}$ & \\
\hline
\end{tabular}


$(p<0.05)$ in all inoculation groups, but comparable in $\mathrm{G} 2$, G5 and G6, while G4 had the lowest GnRH concentration.

\section{Follicle stimulating hormone concentration}

The changes in the mean concentration of FSH in all groups are summarized in Table 3 . There were no changes in FSH in all groups after $6 \mathrm{~h}$, while at $12 \mathrm{~h} \mathrm{FSH}$ was lower $(p<0.05)$ in G3 and by $48 \mathrm{~h} \mathrm{G7}$ had a lower FSH concentration among the inoculation groups. After $48 \mathrm{~h}$, the concentration of $\mathrm{FSH}$ was comparable in all inoculation groups but lower $(p<0.05)$ than the control group. Similarly, the level of FSH declined gradually down the various inoculation groups as time elapsed.

\section{Luteinizing hormone concentration}

The changes in mean concentration of LH in all groups are summarized in Table 4. After $4 \mathrm{~h}$ of inoculation, G3, G4, G5 and G7 had the lowest $(p<0.05)$ concentration of LH. However, there were no changes among the inoculation groups during other sampling periods. Furthermore, the concentration of LH declined down the inoculation groups as time elapsed and were lower $(p<0.05)$ than the control group.

\section{Estradiol concentration}

The changes in mean concentration of EST in all groups are summarized in Table 5. After 6, 8, 10 and $12 \mathrm{~h}$ of inoculation, EST concentration was lower $(p<0.05)$ in G3 when compared to other inoculation groups. After $24 \mathrm{~h}$, EST concentration was lower $(p<0.05)$ in all inoculation groups in comparison to the control. Similarly, EST concentration decreased gradually in all inoculation groups as time elapsed.

\section{Progesterone concentration}

The changes in mean PG concentration in all groups are summarized in Table 6. The concentration of PG was comparable in all inoculation groups and control after $24 \mathrm{~h}$. However, after $4 \mathrm{~h}$, all inoculation groups had a lower $(p<0.05)$ PG concentration in comparison to the control. Similarly, PG concentration gradually declined in all inoculation groups as time elapsed.

\section{Discussion}

Previous study by Jesse et al. [9] in mouse models had shown the presence of both reproductive organ lesions

Table 4 Changes in mean concentration of Luteinizing hormone in prepubertal buffalo heifers following inoculation with Pasteurella multocida B: 2 and its immunogens (LPS and OMP)

\begin{tabular}{|c|c|c|c|c|c|c|c|}
\hline \multirow[t]{2}{*}{$\begin{array}{l}\text { Time } \\
\text { (hr) }\end{array}$} & \multirow{2}{*}{$\begin{array}{l}\text { Inoculated with PBS } \\
\text { Control -G1 }\end{array}$} & \multirow{2}{*}{$\begin{array}{l}\text { Inoculated with P.multocida B:2 } \\
\text { Oral route }-\mathrm{G} 2\end{array}$} & \multirow[b]{2}{*}{$\begin{array}{l}\text { Subcutaneous } \\
\text { route - G3 }\end{array}$} & \multicolumn{2}{|c|}{$\begin{array}{l}\text { Inoculated with LPS extracted } \\
\text { from P.multocida B:2 }\end{array}$} & \multicolumn{2}{|c|}{$\begin{array}{l}\text { Inoculated with OMPs extracted } \\
\text { from P.multocida } \mathrm{B}: 2\end{array}$} \\
\hline & & & & $\begin{array}{l}\text { Oral } \\
\text { route- G4 }\end{array}$ & $\begin{array}{l}\text { Intravenous } \\
\text { route - G5 }\end{array}$ & $\begin{array}{l}\text { Oral } \\
\text { route- G } 6\end{array}$ & $\begin{array}{l}\text { Subcutaneous } \\
\text { route- - G7 }\end{array}$ \\
\hline$\overline{0}$ & $0.51 \pm 0.01^{a}$ & $0.52 \pm 0.01^{a}$ & $0.53 \pm 0.00^{\mathrm{a}}$ & $0.49 \pm 0.01^{a}$ & $0.48 \pm 0.01^{a}$ & $0.52 \pm 0.01^{a}$ & $0.51 \pm 0.01^{a}$ \\
\hline 2 & $0.50 \pm 0.00^{\mathrm{a}}$ & $0.43 \pm 0.01^{b}$ & $0.43 \pm 0.01^{b}$ & $0.48 \pm 0.02^{\mathrm{ab}}$ & $0.42 \pm 0.01^{b}$ & $0.5 \pm 0.01 a$ & $0.44 \pm 0.01^{b}$ \\
\hline 4 & $0.52 \pm 0.01^{\mathrm{a}}$ & $0.41 \pm 0.00 c$ & $0.39 \pm 0.01^{c}$ & $0.43 \pm 0.01^{c}$ & $0.40 \pm 0.00^{c}$ & $0.48 \pm 0.01^{b}$ & $0.41 \pm 0.01^{c}$ \\
\hline 6 & $0.50 \pm 0.01^{\mathrm{a}}$ & $0.39 \pm 0.01^{b}$ & $0.36 \pm 0.01^{b}$ & $0.40 \pm 0.00^{b}$ & $0.38 \pm 0.02^{b}$ & $0.42 \pm 0.02^{b}$ & $0.38 \pm 0.01^{b}$ \\
\hline 8 & $0.49 \pm 0.01^{a}$ & $0.38 \pm 0.01 b$ & $0.34 \pm 0.01^{b}$ & $0.39 \pm 0.01^{b}$ & $0.37 \pm 0.00^{b}$ & $0.38 \pm 0.01^{b}$ & $0.36 \pm 0.01^{b}$ \\
\hline 10 & $0.48 \pm 0.01^{a}$ & $0.37 \pm 0.01^{b}$ & $0.30 \pm 0.00^{b}$ & $0.38 \pm 0.01^{b}$ & $0.37 \pm 0.01^{b}$ & $0.38 \pm 0.02^{b}$ & $0.34 \pm 0.02^{b}$ \\
\hline 12 & $0.49 \pm 0.01^{\mathrm{a}}$ & $0.35 \pm 0.02^{b}$ & $0.28 \pm 0.01^{b}$ & $0.36 \pm 0.01^{b}$ & $0.36 \pm 0.01^{b}$ & $0.37 \pm 0.01^{b}$ & $0.33 \pm 0.01^{b}$ \\
\hline 24 & $0.51 \pm 0.01^{\mathrm{a}}$ & $0.33 \pm 0.00^{b}$ & & $0.35 \pm 0.02^{b}$ & $0.34 \pm 0.01^{b}$ & $0.36 \pm 0.01^{b}$ & $0.32 \pm 0.01^{b}$ \\
\hline 36 & $0.51 \pm 0.00^{\mathrm{a}}$ & $0.32 \pm 0.01^{b}$ & & $0.35 \pm 0.01^{b}$ & $0.33 \pm 0.01^{b}$ & $0.34 \pm 0.02^{b}$ & $0.31 \pm 0.01^{b}$ \\
\hline 48 & $0.49 \pm 0.02^{\mathrm{a}}$ & $0.31 \pm 0.01^{b}$ & & $0.33 \pm 0.01^{b}$ & $0.31 \pm 0.01^{b}$ & $0.32 \pm 0.00^{b}$ & $0.31 \pm 0.02^{b}$ \\
\hline 60 & $0.48 \pm 0.01^{a}$ & $0.30 \pm 0.00^{b}$ & & $0.32 \pm 0.01^{b}$ & $0.31 \pm 0.02^{b}$ & $0.30 \pm 0.00^{b}$ & $0.29 \pm 0.01^{b}$ \\
\hline 72 & $0.53 \pm 0.00 a$ & $0.30 \pm 0.00^{b}$ & & $0.30 \pm 0.00^{b}$ & $0.28 \pm 0.01^{b}$ & $0.28 \pm 0.01^{b}$ & $0.28 \pm 0.02^{b}$ \\
\hline 120 & $0.51 \pm 0.01^{a}$ & $0.29 \pm 0.01^{b}$ & & $0.30 \pm 0.01^{b}$ & $0.26 \pm 0.01^{b}$ & $0.26 \pm 0.01^{b}$ & \\
\hline 168 & $0.50 \pm 0.01^{a}$ & $0.28 \pm 0.01^{b}$ & & $0.28 \pm 0.01^{b}$ & $0.25 \pm 0.01^{b}$ & $0.25 \pm 0.01^{b}$ & \\
\hline 216 & $0.52 \pm 0.01^{a}$ & $0.28 \pm 0.02^{b}$ & & $0.27 \pm 0.01^{b}$ & $0.23 \pm 0.0115^{b}$ & $0.24 \pm 0.02^{b}$ & \\
\hline 264 & $0.50 \pm 0.00^{\mathrm{a}}$ & $0.27 \pm 0.01^{b}$ & & $0.25 \pm 0.02^{b}$ & $0.22 \pm 0.01^{b}$ & $0.22 \pm 0.00^{b}$ & \\
\hline 312 & $0.51 \pm 0.01^{a}$ & $0.26 \pm 0.01^{b}$ & & $0.24 \pm 0.01^{b}$ & $0.22 \pm 0.01^{b}$ & $0.22 \pm 0.01^{b}$ & \\
\hline 360 & $0.50 \pm 0.00^{\mathrm{a}}$ & $0.24 \pm 0.003^{b}$ & & $0.24 \pm 0.01^{b}$ & $0.21 \pm 0.01^{b}$ & $0.22 \pm 0.01^{b}$ & \\
\hline 408 & $0.49 \pm 0.01^{a}$ & $0.22 \pm 0.01^{b}$ & & $0.22 \pm 0.01^{b}$ & $0.21 \pm 0.003^{b}$ & $0.21 \pm 0.003^{b}$ & \\
\hline 456 & $0.50 \pm 0.01^{\mathrm{a}}$ & $0.23 \pm 0.01^{b}$ & & $0.22 \pm 0.01^{\mathrm{b}}$ & $0.22 \pm 0.01^{b}$ & $0.20 \pm 0.003^{b}$ & \\
\hline 504 & $0.50 \pm 0.01^{a}$ & $0.23 \pm 0.01^{b}$ & & $0.22 \pm 0.01^{b c}$ & $0.20 \pm 0.00^{c}$ & $0.2 \pm 0.01^{\mathrm{bc}}$ & \\
\hline
\end{tabular}

All values are expressed as mean $\pm \mathrm{SE} ; \mathrm{a}, \mathrm{b}, \mathrm{c}, \mathrm{d}, \mathrm{e}, \mathrm{f}, \mathrm{g}$, values with superscript within rows are significantly different at $P<0.05$ 
Table 5 Changes in mean concentration of Estradiol hormone in prepubertal buffalo heifers following inoculation with Pasteurella multocida B: 2 and its immunogens (LPS and OMP)

\begin{tabular}{|c|c|c|c|c|c|c|c|}
\hline \multirow[t]{2}{*}{$\begin{array}{l}\text { Time } \\
\text { (hr) }\end{array}$} & \multirow{2}{*}{$\begin{array}{l}\text { Inoculated with } \\
\text { phosphate buffer } \\
\text { saline } \\
\text { Control -G1 }\end{array}$} & \multicolumn{2}{|c|}{ Inoculated with P.multocida B:2 } & \multicolumn{2}{|c|}{$\begin{array}{l}\text { Inoculated with LPS extracted } \\
\text { from P.multocida B:2 }\end{array}$} & \multicolumn{2}{|c|}{$\begin{array}{l}\text { Inoculated with OMPs extracted } \\
\text { from P.multocida B:2 }\end{array}$} \\
\hline & & Oral route $-\mathrm{G} 2$ & Subcutaneous route - G3 & $\begin{array}{l}\text { Oral } \\
\text { route- G4 }\end{array}$ & $\begin{array}{l}\text { Intravenous } \\
\text { route - G5 }\end{array}$ & $\begin{array}{l}\text { Oral } \\
\text { route - G } 6\end{array}$ & $\begin{array}{l}\text { Subcutaneous } \\
\text { route - G7 }\end{array}$ \\
\hline 0 & $51.26 \pm 0.56^{a}$ & $51.43 \pm 0.00^{\mathrm{a}}$ & $49.99 \pm 0.45^{\mathrm{ab}}$ & $48.91 \pm 0.05^{b}$ & $50.72 \pm 0.42^{a}$ & $49.19 \pm 0.11^{\mathrm{ab}}$ & $48.32 \pm 0.58^{b}$ \\
\hline 2 & $52.19 \pm 0.02^{\mathrm{a}}$ & $41.12 \pm 0.01^{d}$ & $43.99 \pm 0.01^{b c}$ & $43.57 \pm 0.33^{b c}$ & $42.96 \pm 0.02^{c d}$ & $41.13 \pm 0.08^{d}$ & $44.32 \pm 0.02^{\mathrm{b}}$ \\
\hline 4 & $48.16 \pm 0.01^{\mathrm{a}}$ & $40.65 \pm 0.19^{c d}$ & $32.55 \pm 0.51^{d}$ & $41.46 \pm 0.01^{c}$ & $40.16 \pm 0.58^{\mathrm{cd}}$ & $40.46 \pm 0.27^{\mathrm{cd}}$ & $42.61 \pm 0.03^{b}$ \\
\hline 6 & $50.01 \pm 0.00^{\mathrm{a}}$ & $39.51 \pm 0.00^{\mathrm{b}}$ & $30.31 \pm 0.18^{f}$ & $38.74 \pm 0.15^{d}$ & $39.07 \pm 0.00^{c}$ & $39.07 \pm 0.00^{c}$ & $38.22 \pm 0.052^{e}$ \\
\hline 8 & $48.33 \pm 0.58^{\mathrm{a}}$ & $37.47 \pm 0.64^{\mathrm{ab}}$ & $27.76 \pm 0.14^{d}$ & $36.18 \pm 0.10^{\mathrm{b}}$ & $38.11 \pm 0.01^{\mathrm{ab}}$ & $38.89 \pm 0.51^{\mathrm{ab}}$ & $35.24 \pm 0.017^{c}$ \\
\hline 10 & $48.11 \pm 0.02^{\mathrm{a}}$ & $36.21 \pm 0.00^{c}$ & $26.66 \pm 0.38^{f}$ & $34.98 \pm 0.01^{d}$ & $37.76 \pm 0.14^{b}$ & $35.31 \pm 0.18^{d}$ & $29.7 \pm 0.64^{e}$ \\
\hline 12 & $50.31 \pm 0.10^{a}$ & $32.57 \pm 0.25^{c}$ & $20.33 \pm 0.00^{e}$ & $34.72 \pm 0.12^{\mathrm{bc}}$ & $36.78 \pm 0.13^{b}$ & $34.76 \pm 0.44^{\mathrm{bc}}$ & $29.85 \pm 0.02^{d}$ \\
\hline 24 & $51.22 \pm 0.00^{a}$ & $31.19 \pm 0.02^{c}$ & & $33.91 \pm 0.58^{b}$ & $32.84 \pm 0.49^{b}$ & $30.06 \pm 0.00^{d}$ & $28.34 \pm 0.06^{e}$ \\
\hline 36 & $48.41 \pm 0.08^{\mathrm{a}}$ & $30.88 \pm 0.07^{c}$ & & $33.02 \pm 0.00^{b}$ & $30.35 \pm 0.00^{c d}$ & $29.92 \pm 0.53^{d}$ & $28.77 \pm 0.13^{d}$ \\
\hline 48 & $50.73 \pm 0.00^{\mathrm{a}}$ & $30.43 \pm 0.58^{b c}$ & & $31.33 \pm 0.19^{b}$ & $30.12 \pm 0.58^{\mathrm{bcd}}$ & $27.18 \pm 0.58^{d}$ & $27.99 \pm 0.01^{c d}$ \\
\hline 60 & $49.05 \pm 0.58^{a}$ & $28.18 \pm 0.02^{\mathrm{bc}}$ & & $30.93 \pm 0.04^{b}$ & $28.17 \pm 0.10^{\mathrm{bcd}}$ & $26.14 \pm 0.58^{\mathrm{cd}}$ & $25.43 \pm 0.10^{d}$ \\
\hline 72 & $52.33 \pm 0.06^{a}$ & $28.04 \pm 0.00^{d}$ & & $31.2 \pm 0.5774^{c}$ & $36.78 \pm 0.13^{b}$ & $24.41 \pm 0.50^{\mathrm{e}}$ & $22.17 \pm 0.00^{f}$ \\
\hline 120 & $49.13 \pm 0.05^{a}$ & $27.59 \pm 0.34^{c}$ & & $28.37 \pm 0.00^{b}$ & $26.34 \pm 0.19^{d}$ & $23.96 \pm 0.02^{\mathrm{e}}$ & \\
\hline 168 & $52.19 \pm 0.04^{a}$ & $26.78 \pm 0.13^{b}$ & & $26.66 \pm 0.38^{b}$ & $24.03 \pm 0.00^{b}$ & $22.19 \pm 0.00^{c}$ & \\
\hline 216 & $51.64 \pm 0.21^{a}$ & $26.33 \pm 0.00^{b}$ & & $26.31 \pm 0.40^{b c}$ & $22.47 \pm 0.31^{b c}$ & $22.35 \pm 0.57^{c}$ & \\
\hline 264 & $48.16 \pm 0.58^{a}$ & $26.42 \pm 0.66^{b}$ & & $25.93 \pm 0.54^{b c}$ & $22.15 \pm 0.02^{c}$ & $22.49 \pm 0.38^{b c}$ & \\
\hline 312 & $48.41 \pm 0.02^{a}$ & $24.98 \pm 0.23^{b}$ & & $24.06 \pm 0.04^{c}$ & $21.14 \pm 0.02^{c}$ & $22.01 \pm 0.56^{c}$ & \\
\hline 360 & $48.1 \pm 0.58^{\mathrm{a}}$ & $24.09 \pm 0.18^{b}$ & & $23.54 \pm 0.27^{\mathrm{bc}}$ & $20.94 \pm 0.26^{c}$ & $20.21 \pm 0.58^{c}$ & \\
\hline 408 & $50.73 \pm 0.16^{a}$ & $22.27 \pm 0.15^{b}$ & & $22.2 \pm 0.318^{b c}$ & $20.91 \pm 0.43^{c d}$ & $19.87 \pm 0.50^{d}$ & \\
\hline 456 & $50.2 \pm 0.058^{a}$ & $20.17 \pm 0.10^{c}$ & & $21.88 \pm 0.29^{c}$ & $20.66 \pm 0.25^{c}$ & $19.43 \pm 0.00^{d}$ & \\
\hline 504 & $49.53 \pm 0.38^{a}$ & $19.99 \pm 0.01^{\mathrm{bc}}$ & & $21.09 \pm 0.00^{b}$ & $20.03 \pm 0.16^{b c}$ & $18.18 \pm 0.10^{c}$ & \\
\hline
\end{tabular}

All values are expressed as mean $\pm \mathrm{SE} ; \mathrm{a}, \mathrm{b}, \mathrm{c}, \mathrm{d}, \mathrm{e}, \mathrm{f}, \mathrm{g}$, values with superscript within rows are significantly different at $P<0.05$

and pituitary lesions in both male and female mice inoculated with P. multocida and its LPS. The lesions reported were both inflammatory and degenerative lesions in these organs with the $P$. multocida group showing more lesion severity and increased testosterone level than the LPS group. However, estrogen and progesterone in female mice were higher in the LPS group [9]. Similarly, a recent report by Ibrahim et al. $[10,11]$ showed evidence of reproductive pathological lesions characterized by degenerative and inflammatory changes in the ovaries, uterus, vagina, the uterine horns and supramammary glands of pre-pubertal buffalo heifers inoculated with $P$. multocida and its immunogens. In the study, lesion severity was more severity in the OMPs inoculation group than in the P. multocida and LPS groups $[10,11]$. In this study, we observed histopathological changes in the anterior pituitary gland and these changes were more severe following inoculation of $P$. multocida B:2 subcutaneously and its OMPs both orally and subcutaneously. This is in agreement with the previous study by Jesse et al. [9] in mice, which showed pituitary gland lesions following P.multocida B:2 and LPS inoculation. However, the lesion severity in mice following oral inoculation of $P$. multocida $\mathrm{B}: 2$ was higher than what was observed in buffaloes in this study. This may be attributed to the body mass index in the buffaloes as well as differences in the digestive tract of the buffalo and the mice; whilst the inoculum goes directly into the stomach of the mice, in the buffalo, it passes through the fore stomach (rumen, reticulum and omasum) thus prolonging the time of absorption and incubation period. On the other hand the severity of lesions in the pituitary gland following inoculation of OMPs is similar to the severity of reproductive lesions observed in the buffaloe calves following OMPs inoculation [11]. This indicates that the bacterial OMPs is perhaps one of the most lethal components of $P$. multocida B:2 serotype.

In this study, we observed decreased hormonal concentrations of GnRH, LH, FSH, EST and PG in all the inoculation groups. This decline in the hormonal concentrations increased as the time of inoculation elapsed, 
Table 6 Changes in mean concentration of Progesterone hormone in Pre-pubertal buffalo heifers following inoculation with Pasteurella multocida B: 2 and its immunogens (LPS and OMP)

\begin{tabular}{|c|c|c|c|c|c|c|c|}
\hline \multirow[t]{2}{*}{$\begin{array}{l}\text { Time } \\
\text { (hr) }\end{array}$} & \multirow{2}{*}{$\begin{array}{l}\text { Inoculated } \\
\text { with PBS } \\
\text { Control G1 }\end{array}$} & \multicolumn{2}{|c|}{ Inoculated with P.multocida B:2 } & \multicolumn{2}{|c|}{$\begin{array}{l}\text { Inoculated with LPS extracted } \\
\text { from P.multocida B:2 }\end{array}$} & \multicolumn{2}{|c|}{$\begin{array}{l}\text { Inoculated with OMPs extracted } \\
\text { from P.multocida B:2 }\end{array}$} \\
\hline & & Oral route G2 & Subcutaneous route - G3 & Oral route G4 & Intravenous route - G5 & Oral route G 6 & Subcutaneous route - G7 \\
\hline 0 & $1.64 \pm 0.01^{a}$ & $1.68 \pm 0.17^{a}$ & $1.67 \pm 0.06^{a}$ & $1.66 \pm 0.19^{a}$ & $1.7 \pm 0.00^{\mathrm{a}}$ & $1.64 \pm 0.00^{\mathrm{a}}$ & $1.69 \pm 0.06^{a}$ \\
\hline 2 & $1.70 \pm 0.017^{\mathrm{a}}$ & $1.22 \pm 0.06^{\mathrm{ab}}$ & $1.04 \pm 0.00^{b}$ & $1.22 \pm 0.01^{\mathrm{ab}}$ & $1.34 \pm 0.07^{\mathrm{ab}}$ & $1.32 \pm 0.12^{\mathrm{ab}}$ & $1.12 \pm 0.00^{b}$ \\
\hline 4 & $1.65 \pm 0.12^{\mathrm{a}}$ & $0.9 \pm 0.00^{e}$ & $0.86 \pm 0.06^{e}$ & $1.12 \pm 0.00^{c}$ & $1.2 \pm 0.00^{b}$ & $1.13 \pm 0.01^{c}$ & $1.02 \pm 0.00^{d}$ \\
\hline 6 & $1.65 \pm 0.01^{\mathrm{a}}$ & $0.83 \pm 0.06^{c}$ & $0.67 \pm 0.10^{c}$ & $0.93 \pm 0.04^{b c}$ & $1.01 \pm 0.00^{\mathrm{b}}$ & $0.96 \pm 0.02^{\mathrm{bc}}$ & $0.93 \pm 0.01^{b c}$ \\
\hline 8 & $1.69 \pm 0.17^{a}$ & $0.76 \pm 0.12^{b}$ & $0.54 \pm 0.01^{b}$ & $0.86 \pm 0.08^{b}$ & $0.92 \pm 0.01^{b}$ & $0.92 \pm 0.01^{\mathrm{b}}$ & $0.89 \pm 0.06^{b}$ \\
\hline 10 & $1.64 \pm 0.11^{\mathrm{a}}$ & $0.73 \pm 0.01^{c d}$ & $0.48 \pm 0.00^{\mathrm{e}}$ & $0.82 \pm 0.02^{\mathrm{bc}}$ & $0.84 \pm 0.02^{b c}$ & $0.88 \pm 0.00^{b}$ & $0.66 \pm 0.04^{d}$ \\
\hline 12 & $1.63 \pm 0.17^{a}$ & $0.64 \pm 0.01^{b}$ & $0.41 \pm 0.01^{d}$ & $0.78 \pm 0.06^{b}$ & $0.76 \pm 0.01^{b}$ & $0.79 \pm 0.06^{b}$ & $0.49 \pm 0.02^{c}$ \\
\hline 24 & $1.68 \pm 0.06^{a}$ & $0.62 \pm 0.01^{f}$ & & $0.66 \pm 0.01^{c}$ & $0.64 \pm 0.00^{d}$ & $0.74 \pm 0.01^{\mathrm{b}}$ & $0.42 \pm 0.00^{e}$ \\
\hline 36 & $1.67 \pm 0.01^{a}$ & $0.59 \pm 0.00^{b}$ & & $0.61 \pm 0.01^{b}$ & $0.61 \pm 0.04^{b}$ & $0.71 \pm 0.00^{c}$ & $0.38 \pm 0.01^{d}$ \\
\hline 48 & $1.68 \pm 0.1^{\mathrm{a}}$ & $0.54 \pm 0.06^{b}$ & & $0.59 \pm 0.04^{b}$ & $0.58 \pm 0.01^{b}$ & $0.55 \pm 0.01^{b}$ & $0.32 \pm 0.02^{\mathrm{b}}$ \\
\hline 60 & $1.68 \pm 0.17^{a}$ & $0.47 \pm 0.01^{c d}$ & & $0.54 \pm 0.00^{b}$ & $0.53 \pm 0.00^{c}$ & $0.47 \pm 0.01^{c d}$ & $0.28 \pm 0.01^{d}$ \\
\hline 72 & $1.69 \pm 0.11^{\mathrm{a}}$ & $0.44 \pm 0.02^{\mathrm{bcd}}$ & & $0.51 \pm 0.02^{b}$ & $0.48 \pm 0.01^{b c}$ & $0.43 \pm 0.01^{c d}$ & $0.24 \pm 0.01^{d}$ \\
\hline 120 & $1.63 \pm 0.01^{a}$ & $0.31 \pm 0.00^{e}$ & & $0.52 \pm 0.01^{b}$ & $0.44 \pm 0.03^{c}$ & $0.36 \pm 0.01^{d}$ & \\
\hline 168 & $1.64 \pm 0.12^{a}$ & $0.26 \pm 0.015^{c}$ & & $0.48 \pm 0.01^{b}$ & $0.37 \pm 0.01^{b c}$ & $0.35 \pm 0.02^{b c}$ & \\
\hline 216 & $1.7 \pm 0.12^{\mathrm{a}}$ & $0.34 \pm 0.02^{b}$ & & $0.36 \pm 0.02^{b}$ & $0.32 \pm 0.00^{b}$ & $0.32 \pm 0.01^{b}$ & \\
\hline 264 & $1.64 \pm 0.01^{a}$ & $0.29 \pm 0.01^{b}$ & & $0.33 \pm 0.01^{b}$ & $0.31 \pm 0.01^{b}$ & $0.3 \pm 0.00^{b}$ & \\
\hline 312 & $1.65 \pm 0.01^{\mathrm{a}}$ & $0.28 \pm 0.02^{b}$ & & $0.33 \pm 0.01^{b}$ & $0.28 \pm 0.00^{b}$ & $0.29 \pm 0.01^{b}$ & \\
\hline 360 & $1.66 \pm 0.12^{\mathrm{a}}$ & $0.26 \pm 0.01^{c}$ & & $0.33 \pm 0.01^{b}$ & $0.27 \pm 0.01^{c}$ & $0.3 \pm 0.018^{c}$ & \\
\hline 408 & $1.68 \pm 0.12^{\mathrm{a}}$ & $0.24 \pm 0.01^{c}$ & & $0.29 \pm 0.012^{b}$ & $0.25 \pm 0.01^{b c}$ & $0.28 \pm 0.01 b^{c}$ & \\
\hline 456 & $1.7 \pm 0.06^{a}$ & $0.21 \pm 0.00^{c}$ & & $0.27 \pm 0.01^{b c}$ & $0.24 \pm 0.01^{b}$ & $0.26 \pm 0.01 b^{c}$ & \\
\hline 504 & $1.67 \pm 0.03^{a}$ & $0.22 \pm 0.003^{b}$ & & $0.23 \pm 0.01^{b}$ & $0.22 \pm 0.01^{b}$ & $0.23 \pm 0.01^{b}$ & \\
\hline
\end{tabular}

All values are expressed as mean $\pm \mathrm{SE} ; \mathrm{a}, \mathrm{b}, \mathrm{c}, \mathrm{d}, \mathrm{e}, \mathrm{f}, \mathrm{g}$, values with superscript within rows are significantly different at $P<0$

indicating that the more the incubation period, the more the effect of the bacteria and immunogens on hormone production/secretion. The study by Jesse et al. [9] in mouse model showed an increased PG and decreased EST concentrations following oral inoculation of both $P$. multocida B:2 and its bacterial LPS. The difference in the PG concentration with buffaloes in this study may be attributed to the difference in cycling pattern between mice and buffalo, or due to the presence of an active corpus leutem in the mice, since they were not synchronized prior to the experimentation. The decline in the concentrations of reproductive hormones observed here can also be attributed to the lesions observed in the pituitary glands rather than to lesions reported in the reproductive tract $[10,11]$. Since it was observed from this study that the most affected cells were the basophils which consists of the gonadotropes, lower levels of LH and FSH is expected as a result of the reversible (degeneration) or irreversible (necrosis) damage induced by $P$. multocida and its immunogens, especially the OMPs.

The pituitary gland is one of the most important endocrine glands in the body because it controls the activities of most other glands [14]. The different phases of the reproductive cycle are regulated by several sequential events and interactions between hypothalamic releasing hormones, hormones secreted from the pituitary and sex steroid hormones secreted by the ovary. Lack of integration, synchronization or endocrine imbalances at any phase of the sequence may result in reproductive insufficiency [15]. In the normal female animal, the hypothalamus secretes the GnRH which in turn causes the release of $\mathrm{LH}$ and FSH from the anterior pituitary. The FSH stimulates the follicles which grow and release estrogen. Progesterone on the other hand is produced by the corpus leutem within the ovaries [16]. Based on the above, P. multocida B:2 and its immunogens; OMPs and LPS were seen to suppress the hypothalamic production of $\mathrm{GnRH}$, which in turn suppressed the production of LH and FSH produced by the anterior pituitary. Furthermore, a low plasma concentration of FSH and $\mathrm{LH}$ results in poor follicular development and reduced estrogen and progesterone production by the developing follicles. In an earlier study by Faccio et al. [17], the authors reported decreased concentrations of LH, FSH, PG and EST in female rats infected with Trypanosoma evansi. This was attributed to increased production of nitrite, 
advanced oxidation protein products (AOPP), and thiobarbituric acid reactive substances (TBARS) in the infected animals. Although the authors did not determine the levels of GnRH, they proposed the decreased hormonal activity to be associated with suppression of $\mathrm{GnRH}$ production by the hypothalamus due to oxidative damage. This assertion may be true since in this study, we observed decreased levels of GnRH in infected buffalo calves. Although Pasteurella and Trypanosoma have different mechanisms of pathogenesis, the nature of reproductive dysfunction may be similar in the two diseases. Other studies using different bacterial pathogens; Corynebacterium pseudotuberculosis and Brucella mellitensis reported variations in female reproductive hormones and pathological lesions in the female reproductive organs of mice and goats experimentally inoculated with the bacteria $[12,13,18]$. Based on previous studies by Chung et al. [19-21], the inoculation of P. multocida and immogens in buffalo calves resulted in different clinic-pathological changes in the lungs, trachea, heart, liver, spleen, kidney and submandibular lymph nodes. In the study, buffaloes from the P. multocida and OMPs subcutaneous inoculation groups showed more severe gross and histopathological lesions. Similarly, these inoculation groups showed significant changes in hematological and biochemical parameters. In a related study by Marza et al. [22], the inoculation of P. multocida subcutaneously to buffaloes resulted in marked histopathological changes in the brain of buffaloes. Furthermore, there was successful isolation of the bacteria from the brain. This finding is very important and pertinent to this study since the pituitary gland is attached to the brain through the hypophysis. Thus an infection of the brain will certainly extend to the pituitary gland. From this study, it can be said that animals that had survived HS may develop reproductive inefficiency which presents as infertility. This has not been previously reported in literature and is of immense significance in large animal production.

\section{Conclusion}

This study reported for the first time the association between adenohypohyseal lesions, decreased hypothalamic production of GnRH and decreased hormonal levels of LH, FSH, EST and PG in buffalo heifers experimentally inoculated with $P$. multocida type B:2 and its immunogens; LPS and OMPs. Based on these findings, P. multocida and its immunogens can predispose to infertility in buffalo heifers.

\section{Abbreviations}

EDTA: Ethylenediaminetetraacetic acid; EST: Estradiol; FSH: Follicle stimulating hormone; GnRH: Gonadotrophin releasing hormone; HRP: Horseradish peroxidase; HS: Hemorrhagic septicemia; LH: Leutienizing hormone; LPS: Lipopolysaccharide; OMPs: Outer membrane proteins; PG: Progesterone

\section{Acknowledgements}

The authors would like to appreciate the staff of the Department of Veterinary Clinical Studies, Universiti Putra Malaysia; Mr. Mohd Jefri Norsidin, Mr. Yap Keng Chee and Mr. Ganesanmurthi Perumal.

\section{Funding}

The project was funded by the Ministry of Higher Education, Malaysia (Grant No: 5,524,417).

\section{Availability of data and materials}

All data are presented within the manuscript. Raw unanalyzed data are available upon request from Dr. Faez Firdaus Abdullah Jesse.

\section{Authors' contributions}

All authors contributed equally to this work. All authors read and approved the final manuscript.

\section{Competing interests}

The authors declare that they have no competing interests.

\section{Consent for publication}

Not applicable.

\section{Ethics approval and consent to participate}

The experimental procedures conducted here strictly adhered to the guidelines of the animal care and use and was subjected to review and approval by the Institutional Animal Care and Use Committee (IACUC), Faculty of Veterinary Medicine, Universiti Putra Malaysia, reference No. (UPM/ IACUC/AUP-R048/2014)

\section{Publisher's Note}

Springer Nature remains neutral with regard to jurisdictional claims in published maps and institutional affiliations.

\section{Author details}

'Department of Veterinary Clinical Studies, Faculty of Veterinary Medicine, Universiti Putra Malaysia, 43400 Serdang, Malaysia. ${ }^{2}$ Research Centre for Ruminant Diseases, Faculty of Veterinary Medicine, Universiti Putra Malaysia, 43400 Serdang, Malaysia. ${ }^{3}$ BabilTechnical Institute, Al Furat Al-Awsat

Technical University, Al-Hillah, Iraq. ${ }^{4}$ Department of Veterinary Pathology and Microbiology, Faculty of Veterinary Medicine, Universiti Putra Malaysia, 43400 Serdang, Malaysia. ${ }^{5}$ Department of Veterinary Internal Medicine, College of Veterinary Medicine, Al-Qasim Green University, Al-Qassim, Buraidah, Iraq.

${ }^{6}$ Institute of Bioscience, Universiti Putra Malaysia, 43400 Serdang, Malaysia.

Received: 1 June 2016 Accepted: 28 March 2017

Published online: 05 April 2017

References

1. Jamal H, Chua KH, Frederick D, Mahmood AA, Salmah I. Plasmid DNA analysis of pasteurella multocida serotype $b$ isolated from haemorrhagic septicaemia outbreaks in Malaysia. Med J Malaysia. 2005;1:35-9.

2. Eckersall PD, Bell R. Acute phase proteins: Biomarkers of infection and inflammation in veterinary medicine. Vet J. 2010;185:23-7. doi:10.1016/j.tvjl. 2010.04.009

3. Moffatt JH, Harper M, Harrison P, Hale JD, Vinogradov E, Seemann T, Henry R, Crane B, St Michael F, Cox AD, Adler B, Nation RL, Li J, Boyce JD. Colistin resistance in Acinetobacterbaumannii is mediated by complete loss of lipopolysaccharide production. Antimicrob Agents Chemoth. 2010;54:4971-7.

4. Harper M, Cox A, Adler B and Boyce JD. 2011.Pasteurella multocida lipopolysaccharide: The long and the short of it. Vet Microbiol, 153, no 1 (2011): 109-115

5. Raetz CR, Whitfield C. Lipopolysaccharide endotoxins. Annu Rev Biochem. 2002;71:635-700.

6. Abdullah FFJ, Adamu L, Osman AY, Saad MZ, Zakaria Z, Abdullah R, et al. Acute Phase Protein Profile and Clinico-Pathological Changes in Mice Associated with the Infection of Pasteurella multocida Type B and the Bacterial Lipopolysaccharide and Outer Membrane Protein Imminogens. J Anim Vet Adv. 2013;12(2):186-93.

7. Tamás $H$, Keith A-H, John D, Boyce BA. Outer membrane proteins of Pasteurella multocida. Vet Microbiol. 2010;144(1-2):1-17. 
8. Roier S, Fenninger JC, Leitner DR, Rechberger GN, Reidl J, Schild S Immunogenicity of Pasteurella multocida and Mannheimia haemolytica outer membrane vesicles. Int J Med Microbiol. 2013;303(5):247-56.

9. Abdullah FFJ, Adamu L, Tijjani A, Mohammed K, Abba Y, Sadiq MA, Zainal R, Sabu MJB, Saharee AA, Haron AW. Hormonal and Histopathological Alterations in Pituitary Glands and Reproductive Organs of Male and Female Mice Orally Inoculated with Pasteurella Multocida Type B: 2 and its Lipopolysaccharides. Am J Anim Vet Sci. 2015;10(1):23.

10. Ibrahim HH, Abba Y, Ahmed IM, Jesse FFA, Chung ELT, Marza AD, Zamri-Saad M, Omar AR, Bakar MZA, Saharee AA, Haron AW. Molecular detection and pathology of Pasteurella multocida B: 2 in the reproductive system of prepubertal buffalo calves (Bubalus bubalis). Com Clin Pathol. 2016;25:965-71.

11. Ibrahim HH, Jesse FFA, Abba Y, Chung ELT, Marza A. Clinical and histopathological study on reproductive lesions caused by Pasteurella multocida type b2 immunogens in buffalo heifers. Bul J Vet Med. 2016; doi: 10.15547/bjvm.969

12. Othman AM, Abba Y, Jesse FFA, llyasu YM, Saharee AA, Haron AW, ZamriSaad M, Lila MAM. Reproductive Pathological Changes Associated with Experimental Subchronic Corynebacterium pseudotuberculosis Infection in Nonpregnant Boer Does. J Pathogens. 2016;2016:7. Article ID 4624509. doi: $10.1155 / 2016 / 4624509$

13. Jesse FFA, Abba Y, Tijiani A, Sadiq MA, Konto M, Adamu L, Wahid AH, Mohd Azmi ML, Eric LTC, Ab Rahman MF, Mydin NB. Gonado-hypophyseal lesions and reproductive hormonal changes in Brucella melitensis-infected mice and its lipopolysaccharides (LPSs). Com Clin Pathol. 2016;25(1):31-6.

14. Unluhizarci K, Bayram F, Colak R, et al. Clinical case seminar: distinct radiological and clinical appearance of lymphocytic hypophysitis. J Clin Endocrinol Metab. 2011;86:1861-4.

15. Terzano G, Vittoria LB, Borghese A. Overview on Reproductive Endocrine Aspects in Buffalo. J Buff Sci. 2012;1:126-38.

16. Bondurant $\mathrm{RH}$. Inflammation in the bovine female reproductive tract. Anim Sci. 1999;77:101.

17. Faccio L, Aleksandro S, Da S, Alexandre AT, Raqueli TF, Lucas TG, Maira MC Camila BO, Manuela BS, Rafael NM, Nathieli BB, Marta MMF, Silvia GM. Serum levels of $\mathrm{LH}, \mathrm{FSH}$, estradiol and progesterone in female rats experimentally infected by Trypanosoma evansi. Exp Parasitol. 2013; 135(2013):110-5.

18. Othman A, Jesse F, Adamu L, Abba Y, Adza Rina M, Saharee A, Wahid AH, Zamri-Saad M. Changes in serum progesterone and estrogen concentrations in non-pregnant boer does following experimental infection with Corynebacterium pseudotuberculosis. J Vet Adv. 2014;4(5):524-8.

19. Chung ELT, Abdullah FFJ, Adamu L, Marza AD, Ibrahim HH, Zamri-Saad M, Haron AW, Saharee AA, Lila MAM, Omar AR, Bakar MZA. Clinico-pathology, hematology, and biochemistry responses toward Pasteurella multocida Type B: 2 via oral and subcutaneous route of infections. Vet World. 2015;8(6):783.

20. Chung ELT, Abdullah FFJ, Ibrahim HH, Marza AD, Zamri-Saad M, Haron AW, Lila MAM, Norsidin MJ. Clinico-pathology, hematology and biochemistry responses in buffaloes towards Pasteurella multocida type B: 2 immunogen lypopolysaccharide via oral and intravenous routes of infection. Microb Pathog. 2016:91:141-54.

21. Chung ELT, Abdullah FFJ, Marza AD, Saleh WMM, Ibrahim HH, Abba Y, Zamri-Saad M, Haron AW, Saharee AA, Lila MAM, Norsidin MJ. Clinicopathology and hemato-biochemistry responses in buffaloes infected with Pasteurella multocida type B: 2 immunogen outer membrane protein. Microb Pathog. 2017;102:89-101.

22. Marza AD, Abdullah FFJ, Ahmed IM, Chung ELT, Ibrahim HH, Zamri-Saad M, Omar AR, Bakar MZA, Saharee AA, Haron AW, Alwan MJ. The ability of lipopolysaccharide (LPS) of Pasteurella multocida B: 2 to induce clinical and pathological lesions in the nervous system of buffalo calves following experimental inoculation. Microb Pathog. 2017;104:340-7.

\section{Submit your next manuscript to BioMed Central and we will help you at every step:}

- We accept pre-submission inquiries

- Our selector tool helps you to find the most relevant journal

- We provide round the clock customer support

- Convenient online submission

- Thorough peer review

- Inclusion in PubMed and all major indexing services

- Maximum visibility for your research

Submit your manuscript at www.biomedcentral.com/submit 